\title{
Effect Evaluation of Arctic Route Navigation on Port Logistics Competitiveness in China
}

\author{
Dan Liu \\ School of Management \\ Jilin University \\ Changchun, China \\ Haitao Wen \\ School of Management \\ Jilin University \\ Changchun, China
}

\author{
Shun Yao \\ School of Management \\ Jilin University \\ Changchun, China \\ Chun Wang \\ School of Management \\ Jilin University \\ Changchun, China
}

\begin{abstract}
Arctic route navigation will have different effects on the competitiveness of port logistics. This paper selects 5 Arctic Route ports in China, using entropy weight - double base point method, to evaluate the impact of Arctic route navigation on the competitiveness of port logistics from three aspects: agglomeration level, transport capacity and development potential. The evaluation results show that the competitiveness of port logistics in Shanghai is superior to other ports in terms of agglomeration level and development potential, but slightly less in transport capacity. Dalian Port is the most competitive in transport capacity. From the results of comprehensive evaluation, port logistics in Shanghai has the biggest competitive advantage under the background of Arctic route navigation. Finally, according to the evaluation results, the Arctic route ports are divided into three different development levels, and the suitable development orientation of port logistics for various levels is put forward.
\end{abstract}

Keywords-Arctic route; port logistics competitiveness; effect evaluation; gravity model; entropy weight-double base point method

\section{INTRODUCTION}

With the accelerated melting of Arctic sea ice, a brandnew route connecting the Atlantic Ocean and the Pacific Ocean, i.e. the Arctic route appears, this new route has immeasurable economic value. The realization of ice-free navigation on Arctic route will have a significant impact on the strategy, economy and resources of all countries in the world, especially for the countries along the Arctic route and the countries near the Arctic. On January 26, 2018, Chinese government published the White Paper on Arctic Policy for the first time, China's Arctic Policy, which reflects the positive attitude of China towards participating in Arctic activities and cooperation.

So the Arctic route navigation will inevitably change the global maritime transport pattern among Asia, Europe and North America, and will also have a far-reaching impact on port logistics. Therefore, the analysis of impact of Arctic route navigation on port logistics competitiveness will help to define the development direction of port logistics in the context of Arctic route navigation, and to provide a theoretical basis for the full use of port logistics resources.

\section{Selection BASIS AND Data SOURCE OF SAMPLE PORTS}

Zhenfu Li (2016) defined the Arctic route ports in China, taking the total amount of import and export trade of the city where the port is located as the basic definition index, taking the voyage reduction, route density, foreign trade throughput and oil and gas throughput capacity as the competitive definition index for comprehensive evaluation, and selected 26 Arctic route ports in China that meet the standard (See "Table I"). Among them, there are five ports that meet the four competitive indexes, namely Dalian, Tianjin, Qingdao, Shanghai and Ningbo Zhoushan. Therefore, this paper chooses these five ports as sample ports to analyze the impact of Arctic route navigation on port logistics. 
TABLE I. SELECTION OF ARCTIC ROUTE PORTS IN CHINA

\begin{tabular}{|c|c|c|c|}
\hline Index & Dalian & Qinhuangdao & Tangshan \\
\hline Voyage reduction & $\sqrt{ }$ & $\sqrt{4}$ & $\sqrt{ }$ \\
\hline Route density & $\sqrt{ }$ & & \\
\hline Foreign trade throughput & $\sqrt{ }$ & $\sqrt{ }$ & $\sqrt{ }$ \\
\hline Oil and gas throughput throughput & $\sqrt{ }$ & $\sqrt{ }$ & $\sqrt{ }$ \\
\hline Index & Tianjin & Yantai & Weihai \\
\hline Voyage reduction & $\sqrt{ }$ & $\sqrt{ }$ & $\sqrt{ }$ \\
\hline Route density & $\sqrt{ }$ & & \\
\hline Index & Tianjin & Yantai & Weihai \\
\hline Foreign trade throughput & $\sqrt{ }$ & $\sqrt{ }$ & $\sqrt{ }$ \\
\hline Oil and gas throughput throughput & $\sqrt{ }$ & & \\
\hline Index & Qingdao & Rizhao & Lianyungang \\
\hline Voyage reduction & $\sqrt{ }$ & $\sqrt{ }$ & $\sqrt{ }$ \\
\hline Route density & $\sqrt{ }$ & & \\
\hline Foreign trade throughput & $\sqrt{ }$ & & $\sqrt{ }$ \\
\hline Oil and gas throughput throughput & $\sqrt{ }$ & $\sqrt{ }$ & \\
\hline Index & Shanghai & Zhapu & Zhoushan \\
\hline Voyage reduction & $\sqrt{ }$ & $\sqrt{ }$ & $\sqrt{ }$ \\
\hline Route density & $\sqrt{ }$ & & $\sqrt{ }$ \\
\hline Foreign trade throughput & $\sqrt{ }$ & $\sqrt{ }$ & $\sqrt{ }$ \\
\hline Oil and gas throughput throughput & $\sqrt{ }$ & & $\sqrt{ }$ \\
\hline Index & Fuzhou & Quanzhou & Taibei \\
\hline Voyage reduction & $\sqrt{ }$ & $\sqrt{ }$ & \\
\hline Route density & & & $\sqrt{ }$ \\
\hline Foreign trade throughput & $\sqrt{ }$ & & $\sqrt{ }$ \\
\hline Oil and gas throughput throughput & & $\sqrt{ }$ & \\
\hline Index & Xiamen & Shantou & Shenzhen \\
\hline Voyage reduction & $\sqrt{ }$ & $\sqrt{ }$ & $\sqrt{ }$ \\
\hline Route density & $\sqrt{ }$ & & $\sqrt{ }$ \\
\hline Foreign trade throughput & $\sqrt{ }$ & $\sqrt{ }$ & $\sqrt{ }$ \\
\hline \multicolumn{4}{|l|}{ Oil and gas throughput throughput } \\
\hline Index & Guangzhou & Zhoushan & Zhuhai \\
\hline Voyage reduction & & $\sqrt{ }$ & $\sqrt{ }$ \\
\hline Route density & $\checkmark$ & & \\
\hline Foreign trade throughput & $\sqrt{ }$ & $\sqrt{ }$ & $\sqrt{ }$ \\
\hline Oil and gas throughput throughput & $\sqrt{ }$ & & \\
\hline Index & Jiangmen & Gaoxiong & Zhanjiang \\
\hline Voyage reduction & $\sqrt{ }$ & & $\sqrt{ }$ \\
\hline Route density & & $\sqrt{ }$ & \\
\hline Foreign trade throughput & $\sqrt{ }$ & $\sqrt{ }$ & $\sqrt{ }$ \\
\hline Oil and gas throughput throughput & & & $\sqrt{ }$ \\
\hline Index & Xianggang & Wenzhou & \\
\hline Voyage reduction & & $\sqrt{ }$ & \\
\hline Route density & $\sqrt{ }$ & & \\
\hline Foreign trade throughput & $\sqrt{ }$ & $\sqrt{ }$ & \\
\hline Oil and gas throughput throughput & & & \\
\hline
\end{tabular}

${ }^{\text {a. }}$ Reference: Zhenfu Li, etc., Definition of the Arctic Route Ports of China, Area Research and Development [J], Vol. 35, No. 6, Dec. 2016

The data of this paper comes from the statistical bulletin of national economic and social development of each city, China Aviation weekly, China port guide, China port container statistical yearbook and related data websites.

\section{RESEARCH METHODS AND EVALUATION STEPS}

In this paper, entropy weight - double base point method is used to evaluate and analyze the impact of Arctic route navigation on port logistics, entropy weight method is used to determine the weight of each index, and double base point method is used to comprehensively evaluate each index.
Entropy weight method is mainly used to solve the weight problem of evaluation indexes. It takes the amount of decision-making information as the standard to determine the weight of indexes and measure the relative importance of the selected indexes. It can strengthen the scientific nature of the weight and reduce the subjectivity. First, the evaluation judgment matrix is determined, and the index zero dimension is processed, then the entropy value of each index is calculated, and finally the weight of each index is determined.

In essence, the double base point method is a sort method approaching to the ideal solution, which takes the index value of the evaluation object and the closeness degree of the ideal solution as the evaluation standard to determine the 
Calculate the weight of index $\mathrm{j}$.

$$
W_{j}=d_{j} / \sum_{j=1}^{n} d_{j}
$$

Among them, ${ }^{d_{j}}=1-e_{j}$.

B. Sorting Based on Double Base Point Method

1) Establishing normalized attribute matrix

$$
A=\left[\begin{array}{ccc}
a_{11} & \ldots & a_{1 n} \\
\vdots & \ddots & \vdots \\
a_{m 1} & \ldots & a_{m n}
\end{array}\right]=\left[\begin{array}{ccc}
w_{1} r_{11}^{\prime} & \ldots & w_{n} r_{1 n}^{\prime} \\
\vdots & \ddots & \vdots \\
w_{1} r_{1 m}^{\prime} & \ldots & w_{n} r^{\prime}{ }_{m n}
\end{array}\right]
$$

2) Defining ideal point and negative ideal point of index

(8) Ideal point: $P^{+}=\left(P_{1}^{+}, P_{2}^{+}, \ldots \ldots, P_{n}^{+}\right)$

Among them, $P_{i}^{+}=\max _{i}\left\{a_{i j} \mid j=1,2, \ldots \ldots, n ; i=1,2, \ldots \ldots, m\right\}$

(9) Negative ideal point: $P^{-}=\left(P_{1}^{-}, P_{2}^{-}, \ldots \ldots, P_{n}^{-}\right)$

Among them, $P_{i}^{-}=\min _{i}\left\{a_{i j} \mid j=1,2, \ldots \ldots, n ; i=1,2, \ldots \ldots, m\right\}$

3) Determining the distance between the evaluated object and the ideal point and the negative ideal point

(10) Distance from ideal point: ${ }^{d_{i}^{+}=\sqrt{\sum_{j-1}^{n}\left(a_{i j}-p_{i}^{+}\right)^{2}}} \mathrm{i}=1$, $2, \ldots, \mathrm{m}$

(11) Distance from negative ideal point: $d_{i}^{-}=\sqrt{\sum_{j-1}^{n}\left(a_{i j}-p_{i}^{-}\right)^{2}} \quad \mathrm{i}=1,2, \ldots, \mathrm{m}$

4) Determining the degree of preference of each port evaluation value

According to the idea of double base point method, the optimal solution should be the value that is farthest from the negative ideal point and closest to the ideal point. However, in the actual operation and evaluation process, the scheme that meets the two conditions at the same time may not exist. Therefore, the concept of superior degree is used, that is, the ratio of the distance from the negative ideal point to the sum of the distance from the ideal point and the negative ideal point is used to measure, and represented by $u_{i}$.

$$
u_{i}=\frac{d_{i}^{-}}{d_{i}^{-}+d_{i}^{+}}
$$

\section{ANALYSIS OF INFLUENCING FACTORS OF PORT LOGISTICS COMPETITIVENESS AGAINST THE BACKGROUND OF ARCTIC ROUTE NAVIGATION}

After the Arctic route navigation, China's maritime transport pattern will also change, which makes the influencing factors of port logistics competitiveness more complex. This paper analyzes the influencing factors of port logistics competitiveness from three aspects: agglomeration level, transportation capacity and development potential.

When $y_{i j}=0$, then $y_{i j} \times \ln y_{i j}=0$.

4) Determining the index weight 
1) Port conditions: The depth of berths and the capacity of container berths are important factors to determine whether a port is competitive. The higher these two indexes are, the greater the port attraction to goods and large ships will be, and the virtuous circulation level of logistics facilities and storage will also be improved, so as to improve the economic benefits of port logistics.

2) Carrying capacity: The length of the railway line and the handling capacity determine the operation capacity of the port. If these two indicators are highly satisfied, it means that more cargo flows can still be shared in port competitions, and the carrying capacity of the port logistics will be more advantageous after Arctic route navigation.

3) Port service level: The number of port transit boxes and the number of dock loading and unloading machinery can best reflect the service level of a port. At present, the number of port transit boxes has been included in the evaluation index system of each port's transportation capacity. Through these two indicators, we can examine whether the port has the ability to attract cargo after the Arctic route navigation, and then reflect the service level of the port.

\section{Development Potential}

To evaluate the competitiveness of port logistics in the context of Arctic route navigation, we should not only consider the current development status of port logistics, but also examine the development potential of port logistics. Development potential is an important index to evaluate the future development trend of port logistics. This paper selects three indicators to evaluate the development potential of port logistics, namely, port development, economic development and human development.

1) Port development: The annual growth rate of cargo throughput and container throughput can directly reflect whether the port is in a sound development in the operation. Only with a sound development, can the port logistics have greater development potential.

2) Economic development: The amount of foreign investment and fixed asset investment fully reflects the capital advantage of the port in the competition. The greater the capital advantage, the more attractive the port will be in the future development, the port logistics will have more development potential.

3) Human development: The international popularity of the port is constantly improved in the process of trade increase and port construction, which will attract more tourists to visit. Therefore, the human development should not be ignored when evaluating the development potential of port logistics. In this paper, the city's annual passenger throughput and the number of inbound tourists are selected to evaluate the human development potential of the port. caper mainly selects three indicators that can best reflect the impact of the Arctic route on port transportation capacity, namely: port conditions, carrying capacity and port service level. 
route navigation, and referring to the achievements of other scholars on port logistics competitiveness, this paper constructs an evaluation index system including three first level indexes, nine second level indexes and 17 third level indexes. The index system and detailed description are shown in "Table II".

\section{A. Construction of Evaluation Index System}

Based on the analysis of influencing factors of port logistics competitiveness under the background of Arctic

TABLE II. EVALUATION INDEX SySTEM

\begin{tabular}{|c|c|c|}
\hline First level & Second level & Third level \\
\hline \multirow{5}{*}{$\begin{array}{l}\text { Agglomeration } \\
\text { level } B_{1}\end{array}$} & \multirow{2}{*}{ Operation level $\mathrm{B}_{11}$} & route efficiency $\mathrm{B}_{111}$ \\
\hline & & route density $\mathrm{B}_{112}$ \\
\hline & \multirow{2}{*}{ Trade level $\mathrm{B}_{12}$} & trade volume $\mathrm{B}_{121}$ \\
\hline & & oil and gas throughput $\mathrm{B}_{122}$ \\
\hline & Coordination and support $\mathrm{B}_{13}$ & policy environment $\mathrm{B}_{131}$ \\
\hline \multirow{6}{*}{ Transportation capacity $\mathrm{B}_{2}$} & \multirow{2}{*}{ Port conditions $\mathrm{B}_{21}$} & berth depth $\mathrm{B}_{211}$ \\
\hline & & container berth capacity $\mathrm{B}_{212}$ \\
\hline & \multirow{2}{*}{ Carrying capacity $\mathrm{B}_{22}$} & railway line length $B_{221}$ \\
\hline & & handling capacity $\mathrm{B}_{222}$ \\
\hline & \multirow{2}{*}{ Port service level $B_{23}$} & transit boxes $\mathrm{B}_{231}$ \\
\hline & & loading and unloading machinery $\mathrm{B}_{232}$ \\
\hline \multirow{6}{*}{ Development potential $\mathrm{B}_{3}$} & \multirow{2}{*}{ Port development $\mathrm{B}_{31}$} & growth rate of cargo throughput $\mathrm{B}_{311}$ \\
\hline & & growth rate of container throughput $\mathrm{B}_{312}$ \\
\hline & \multirow{2}{*}{ Economic development $\mathrm{B}_{32}$} & foreign investment $\mathrm{B}_{321}$ \\
\hline & & fixed asset investment $B_{322}$ \\
\hline & \multirow{2}{*}{ Human development $\mathrm{B}_{33}$} & passenger throughput $\mathrm{B}_{331}$ \\
\hline & & inbound tourists $\mathrm{B}_{332}$ \\
\hline
\end{tabular}

\section{B. Determination of Index Weight}

All indicators in the evaluation index system constructed in this paper are positive indicators. The evaluation matrix is established according to formula (1) and (2), the evaluation matrix is standardized and the zero dimension index standard value is obtained. The entropy value of the index is determined according to formula (4) and (5). The weights of all levels of indicators are calculated according to formula (6). See "Table III" for details.

TABLE III. WEIGHT DistRIBUTION OF EVALUATION INDEX SySTEM

\begin{tabular}{|c|c|c|c|c|c|}
\hline First & Weight & Second & Weight & Third & Weight \\
\hline \multirow{5}{*}{$\mathrm{B}_{1}$} & \multirow{5}{*}{0.3031} & \multirow{2}{*}{$\mathrm{B}_{11}$} & \multirow{2}{*}{0.1136} & B111 & 0.0483 \\
\hline & & & & B112 & 0.0653 \\
\hline & & \multirow{2}{*}{$\mathrm{B}_{12}$} & \multirow{2}{*}{0.1192} & B121 & 0.066 \\
\hline & & & & B122 & 0.0532 \\
\hline & & $\mathrm{B}_{13}$ & 0.0703 & B131 & 0.0703 \\
\hline \multirow{6}{*}{$\mathrm{B}_{2}$} & \multirow{6}{*}{0.3424} & \multirow{2}{*}{$\mathrm{B}_{21}$} & \multirow{2}{*}{0.1081} & B211 & 0.0538 \\
\hline & & & & B212 & 0.0543 \\
\hline & & \multirow{2}{*}{$\mathrm{B}_{22}$} & \multirow{2}{*}{0.1162} & B221 & 0.0585 \\
\hline & & & & B222 & 0.0577 \\
\hline & & \multirow{2}{*}{$\mathrm{B}_{23}$} & \multirow{2}{*}{0.1181} & B231 & 0.0567 \\
\hline & & & & B232 & 0.0614 \\
\hline \multirow{6}{*}{$\mathrm{B}_{3}$} & \multirow{6}{*}{0.3545} & \multirow{2}{*}{$\mathrm{B}_{31}$} & \multirow{2}{*}{0.1128} & B311 & 0.0493 \\
\hline & & & & B312 & 0.0635 \\
\hline & & \multirow{2}{*}{$\mathrm{B}_{32}$} & \multirow{2}{*}{0.1222} & B321 & 0.0714 \\
\hline & & & & B322 & 0.0508 \\
\hline & & \multirow{2}{*}{$\mathrm{B}_{33}$} & \multirow{2}{*}{0.1195} & B331 & 0.056 \\
\hline & & & & B332 & 0.0635 \\
\hline
\end{tabular}

\section{Determination of the Rank of Superior Degree}

Ideal point and negative ideal point are calculated according to formula (7) and (8).

Positive ideal point: $P^{+}=(0.0483,0.0653,0.066,0.0532,0.0703,0.0583,0.0543,0.0585,0.0577$, $0.0567,0.0614,0.0493,0.0635,0.0714,0.0508,0.056,0.0635)^{T}$

Negative ideal point: $P^{-}=(0,0, \ldots \ldots, 0)^{T}$
According to the formula (10) - (12), the distance between each index of each port and the positive ideal point, the distance between each index of each port and the negative ideal point, and the ranking of superior degree are determined. See "Table IV", "Table V", "Table VI", "Table VII" for details. 
TABLE VII. COMPREHENSIVE EVALUATION RESULTS AND RANKING

\begin{tabular}{|l|l|l|l|l|}
\hline \multicolumn{1}{|c|}{ Port } & $\begin{array}{c}\text { Positive } \\
\text { ideal } \\
\text { point }\end{array}$ & $\begin{array}{c}\text { Negative } \\
\text { ideal } \\
\text { point }\end{array}$ & $\begin{array}{c}\text { superior } \\
\text { degree }\end{array}$ & Rank \\
\hline Dalian & 0.173606 & 0.147735 & 0.459745 & 2 \\
\hline Tianjin & 0.168737 & 0.129673 & 0.434547 & 3 \\
\hline Qingdao & 0.194414 & 0.105789 & 0.352391 & 5 \\
\hline Shanghai & 0.121087 & 0.183381 & 0.602300 & 1 \\
\hline Zhoushan & 0.178954 & 0.112290 & 0.385553 & 4 \\
\hline
\end{tabular}

From the perspective of port agglomeration level, the Arctic route has the greatest impact on the improvement of Shanghai port agglomeration level. Shanghai port is the first in the national container throughput rankings, the volume of foreign trade is the largest in these ports, plus the various preferential policies such as Free Trade Area of Shanghai port, all these factors have contributed to greater advantages of Shanghai port in terms of agglomeration level. The second are Dalian port, Qingdao port, Ningbo Zhoushan port, and the last is Tianjin port.

TABLE V. EVALUATION RESULTS AND RANKING OF PORT TRANSPORTATION CAPACITY

\begin{tabular}{|l|l|l|l|l|}
\hline \multicolumn{1}{|c|}{ Port } & $\begin{array}{c}\text { Positive } \\
\text { ideal point }\end{array}$ & $\begin{array}{c}\text { Negative } \\
\text { ideal point }\end{array}$ & $\begin{array}{c}\text { superior } \\
\text { degree }\end{array}$ & Rank \\
\hline Dalian & 0.070704 & 0.102602 & 0.592030 & 1 \\
\hline Tianjin & 0.088962 & 0.093243 & 0.511747 & 3 \\
\hline Qingdao & 0.113874 & 0.035670 & 0.238525 & 5 \\
\hline Shanghai & 0.092408 & 0.100241 & 0.520330 & 2 \\
\hline Zhoushan & 0.097089 & 0.052970 & 0.352996 & 4 \\
\hline
\end{tabular}

From the perspective of port transport capacity, the Arctic route has the greatest impact on the improvement of Dalian port transport capacity. Dalian port is not only the main transit port in China, but also an important port for crude oil import and unloading. After the Arctic route navigation, not only the trade of oil and gas resources but also the number of goods transit will increase significantly, all of these factors will enhance the transport capacity of Dalian port. The second are Shanghai port, Tianjin port, Ningbo Zhoushan port, and the last is Qingdao port.

TABLE VI. EVALUATION RESUlTS AND RANKING OF PORT DEVELOPMENT POTENTIAL

\begin{tabular}{|l|c|c|c|c|}
\hline \multicolumn{1}{|c|}{ Port } & $\begin{array}{c}\text { Positive } \\
\text { ideal } \\
\text { point }\end{array}$ & $\begin{array}{c}\text { Negative } \\
\text { ideal } \\
\text { point }\end{array}$ & $\begin{array}{c}\text { superior } \\
\text { degree }\end{array}$ & Rank \\
\hline Dalian & 0.127590 & 0.054912 & 0.300883 & 5 \\
\hline Tianjin & 0.101453 & 0.070859 & 0.411226 & 3 \\
\hline Qingdao & 0.113834 & 0.069262 & 0.378283 & 4 \\
\hline Shanghai & 0.043292 & 0.119811 & 0.734571 & 1 \\
\hline Zhoushan & 0.110709 & 0.078326 & 0.414346 & 2 \\
\hline
\end{tabular}

From the perspective of port development potential, Shanghai Port still has the greatest development potential. No matter the container throughput, or the investment and the number of tourists, Shanghai port has far more competitive advantages than other ports. After the Arctic route navigation, it also has the greatest impact on the development potential of Shanghai port, the second are Ningbo Zhoushan port, Tianjin port and Qingdao port, and the last is Dalian port.
According to the three indicators of agglomeration level, transportation capacity and development potential, Shanghai port logistics still has the greatest competitiveness in the final evaluation result. Dalian port will have a more favorable location advantage after Arctic route navigation, and its port logistics competitiveness ranks the second in the comprehensive ranking. Then Tianjin port, Ningbo Zhoushan port and Qingdao port are in proper sequence.

\section{Analysis of Evaluation Results}

According to the results of agglomeration level, transportation capacity, development potential, comprehensive evaluation and superior degree ranking, the five ports selected in this paper can be divided into three different development levels under the background of Arctic route navigation.

Shanghai Port belongs to the first level. Its basic environment and financial environment are the most advantageous, and its economic ties with hinterland are also the most close. Compared with other four ports, Shanghai port is the most competitive, so it can also meet the needs of port logistics best after the Arctic route navigation.

The second level ports include Dalian port, Tianjin port and Qingdao port. Compared with Shanghai port, these three ports have a certain degree of differences in basic environment and their connection with the Arctic route. On the basis of enhancing infrastructure and collecting and distributing level, and giving full play to their advantages in oil and gas handling capacity, they are possible to better meet the cargo diversion brought about by the Arctic route. At the same time, these three ports also have the location advantage for common development, the geographical location is close, the development level is equivalent, so the overall competitiveness can be improved by forming the port strategic alliance.

Ningbo Zhoushan port belongs to the third level port under the background of Arctic route navigation. Compared with the other four ports, its geographical location and port nature have the weakest connection with the Arctic route. It can focus on relevant manufacturing industries, and take the Arctic route regional hub port as its port logistics development direction.

\section{CONCLUSION}

The logistics competition between different ports is becoming increasingly fierce. The Arctic route navigation will not have a favorable impact on all ports' logistics, and 
the competitive position of each port will inevitably change under the opening of the new route. In order to give full play to the competitive advantage of port logistics, it is necessary to accurately evaluate the possible impact on port logistics after the Arctic route navigation. In this paper, the influencing factors of port logistics under the background of Arctic route navigation are divided into three categories: agglomeration level, transportation capacity and development potential. By constructing the evaluation index system and using the entropy weight - double base point method, the impact of Arctic route navigation on port logistics competitiveness is evaluated, in order to provide theoretical reference for the development orientation of China's port logistics after the comprehensive navigation of Arctic route.

\section{REFERENCES}

[1] Zhenfu Li, Qian Zeng, Chao Liu, Definition of the Arctic Route Ports of China, Area Research and Development [J], Vol. 35, No. 6, Dec. 2016.

[2] Zhenfu Li, Chaojun Ding, Qian Zeng, Hierarchy of Chinese Ports for Arctic Route, Navigation of China [J], Vol. 39, No. 3, Sept, 2016.

[3] H Park, MG Lee, A Study on Competitiveness and Effect Analysis for Developing a Port Specialized in Northern Sea Route, J Navig. Port Res. [J], Vol. 39, No. 3, 2015

[4] Dan Zhang, Hao Zhang, Impact of the Arctic Passage's Opening on Chinese Norther Ports and China's Response, China Soft Science [J], Vol. 3, 2014.

[5] Cariou Pierre, Faury Olivier, Relevance of the Northern Sea Route (NSR) for bulk shipping, Transportation Research Part A Policy \& Practice [J], Vol. 78, 2015.

[6] Yu Chen, Guanglu Wen, Fuzzy Comprehensive Evaluation of Port Logistics Capacity based on Information entropy, Logistics Technology [J], Vol. 3, No. 5, 2012.

[7] Hong Wang, Comprehensive Evaluation of Port Logistics Competitivity in International Trade based on Factor Analysis, Logistics Technology [J], Vol. 33, No.1, 2014

[8] Qiuping Yang, Huijuan Zhai, The Influence of New Route on Shipping Industry and Competition Pattern of China's Ports, Public Utilities [J], No. 1, 2017.

[9] Halvor Schøen, Svein Bråhen, The Northern Sea Route versus the Suez Canal: Cases from Bulk Shipping, Journal of Transport Geography [J], Vol. 19, 2011.

[10] Sung-Woo LEE, Ju-Mi SONG, Economic Possibilities of Shipping through Northern Sea Route, The Asian Journal of Shipping and Logistics [J], Vol. 30, No. 3, 2014. 